\section{FDA issues Alzheimer's rethink}

Cognitive benefits alone may be sufficient to secure approval for an Alzheimer's drug, says the agency.

The lowdown: Several failures of Phase III Alzheimer's disease drug candidates have prompted drug developers to embrace earlier intervention strategies (Nature Rev. Drug Discov. 11. 657-660; 2012). But trials that test new drugs in asymptomatic and prodromal patients come with several new regulatory challenges. For one, the US Food and Drug Administration (FDA) has expected Alzheimer's drug candidates to deliver cognitive and functional improvements, but functional improvements are particularly hard to show in these settings. "We simply do not yet have drug development tools that are validated to provide measures of function in patients with Alzheimer's disease before the onset of overt dementia," write agency employees Russell Katz and Nicholas Kozauer in an article summarizing the regulatory challenges (N. Engl.J. Med. $368,1169-1171 ; 2013)$. The article goes on to detail recently released guidance (go.nature. $\mathrm{com} / \mathrm{magetg}$ ) that could address current shortfalls (see figure below for a schematic of new approval requirements).

"It might be feasible to approve a drug through the FDA's accelerated approval pathway on the basis of assessment of cognitive outcome alone," the authors write. "It remains possible that an effect of an intervention on one or more biomarkers could someday be accepted as predictive of a clinical benefit, but further research will clearly be needed before the effect of an intervention on a single biomarker alone could be considered an adequate surrogate measure for the purposes of accelerated approval of a candidate drug for early Alzheimer's disease," they add.

The cautiously worded article and discussion of accelerated approval reflects a willingness on the FDA's part to engage with the challenges for Alzheimer's drug development, but also highlights that a lot of work still needs to be done to establish appropriate end points, biomarkers and benefit-risk balances.

\begin{tabular}{|c|c|c|c|}
\hline $\begin{array}{l}\text { Disease } \\
\text { stage }\end{array}$ & $\begin{array}{l}\text { Subtle cognitive } \\
\text { deficits alone }\end{array}$ & $\begin{array}{l}\text { - Increasing cognitive } \\
\text { deficits } \\
\text { - Detectable functional } \\
\text { deficits }\end{array}$ & Dementia \\
\hline $\begin{array}{l}\text { FDA } \\
\text { approval }\end{array}$ & $\begin{array}{l}\text { Accelerated, based on } \\
\text { an effect on cognition }\end{array}$ & $\begin{array}{l}\text { Standard, based on a } \\
\text { single combined measure } \\
\text { of cognition and function }\end{array}$ & $\begin{array}{l}\text { Standard, based on } \\
\text { co-primary measures of } \\
\text { cognition and function } \\
\text { or global rating }\end{array}$ \\
\hline
\end{tabular}

\section{Big expectations for Biogen's small MS drug}

US and European regulators approved Biogen Idec's dimethyl fumarate (BG-12) for the treatment of relapsing-remitting multiple sclerosis (RRMS), setting the stage for an MS market reshuffle and blockbuster expectations. The lowdown: Dimethyl fumarate is an immunomodulatory small molecule with a mass of just $144 \mathrm{~g}$ per mol. Although its mechanism of action is unknown, it has been

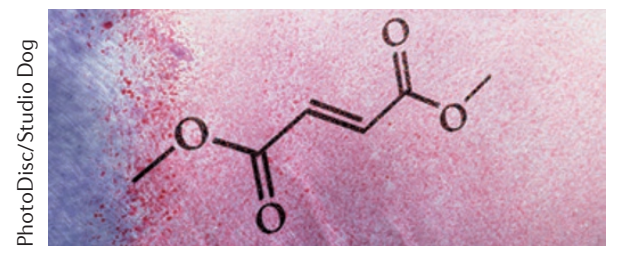

shown to activate the NRF2 (also known as NFE2L2) antioxidant response pathway. First used medically in the 1950 s as a treatment for psoriasis, Fumapharm and Biogen Idec started working on the drug together for MS in 2003. (Dimethyl fumarate was also until recently used to prevent mould from growing in furniture.)

Two pivotal trials of the oral drug in around 2,000 patients both met their primary end points. In one, the drug nearly halved the number of patients who had relapsed at 2 years when compared to placebo ( $27 \%$ versus $46 \%$ ). In the second, the drug nearly halved the annualized relapse rate versus placebo $(0.224$ versus 0.401 ). Adverse effects noted in the trials included reductions in white blood cell counts, flushing, nausea, vomiting and diarrhoea. Based on the promising efficacy, relatively clean safety profile and oral delivery, many analysts expect the drug to displace much of its disease-modifying competition, which includes interferon betas, Teva's glatiramer acetate, Biogen Idec's natalizumab and Novartis's fingolimod, the first oral disease-modifying MS drug to make it to the market.

BioMed Tracker forecasts annual worldwide sales of US $\$ 5.7$ billion for dimethyl fumarate by 2018. Biogen Idec has priced the drug at just under $\$ 55,000$ per year, a discount of around $9 \%$ from fingolimod.

\section{Mini-Sentinel saves dabigatran}

A case study of the FDA's active pharmacovigilance system shows how insurance-claim data were used to examine adverse event reports and exonerate dabigatran.

The lowdown: When the FDA approved Boehringer Ingelheim's dabigatran in October 2010, the cardiology community welcomed the anticoagulant as a much-needed warfarin replacement.

But when doctors started reporting far more bleeding adverse events than the agency had anticipated for the direct thrombin inhibitor, regulators needed to reassess its safety profile.

To understand whether the reported events reflected a misalignment of clinical trial data and the real risk of bleeding, or just a tendency for doctors to submit more adverse event reports for recently approved drugs than for older medications, the FDA turned to mini-Sentinel, an active pharmacovigilance project that queries electronic health-care data such as insurance claims. Insurance claims reports from a 14-month period showed that the relative incidence of gastrointestinal and intracranial bleeding with dabigatran was 1.6 and 0.8 events per 100,000 days at risk, compared with 3.5 and 2.4 for warfarin (N. Engl. J. Med. 368, 1272-1274; 2013). "We believe that the large number of reported cases of bleeding associated with dabigatran provides a salient example of stimulated reporting. In this case, such reporting provided a distorted estimate of the comparative bleeding rates associated with dabigatran and warfarin in clinical practice," agency officials wrote in the case study. Additional analyses are underway to confirm the conclusions.

The mini-Sentinel project can probe data on over 169 million patients, contributed by 18 participating data partners, and is being trialled in several different pharmacovigilance analyses (Nature Rev. Drug Discov. 11, 255-257; 2012). 